\title{
Physical Activity in the Workplace - Making the Healthy Choice the Easy Choice
}

\author{
Jaclyn Hadfield, Ph.D. \\ Carol Kennedy-Armbruster, Ph.D. \\ Lesa Huber, Ph.D. \\ Susan Middlestadt, Ph.D. \\ Indiana University - Bloomington - School of Public Health
}

\begin{abstract}
Background: Engaging in physical activity in the workplace is important to address to combat the negative health outcomes associated with physical inactivity and prolonged sitting.

Aim: This study aims to identify efforts that increase light neuromotor physical activity in university workplaces for sedentary employees.

Methods: Sub-study 1 examined 15 intervention employees and 10 control employees. MANOVA was used to examine average number of days employees did three movements at work between groups over an eight-week period. Sub-study 2 examined 56 employees and measured three beliefs towards employee intention to do the movements at work. A linear regression examined the significance of the beliefs in predicting employee intention.

Results: MANOVA results showed a significant effect between groups on the average number of days employees did three movements over an eight-week period of time, $F(3,21)=3.16 ; p<.05$. The adjusted $\mathrm{R}$-squared predicting intention from the three beliefs was $.343(p<.001)$. Participants' belief in how 'easy' doing the movements would be significantly predicted intention scores $(\beta=.467 ; p<.001)$ as did the 'popular' belief $(\beta=.371 ; p<.01)$.

Conclusion: Worksite group physical activity programs can increase the frequency employees get up and move at work. Employee beliefs of how easy or popular a behavior is can significantly predict intention to do neuromotor movements in workplaces.
\end{abstract}

Submitted 19 February 2020: accepted 28 June 2020

Keywords: physical activity, health behavior, worksite, sitting time, neuromotor

Engaging in physical activity (PA) in the workplace is important to address in order to combat the negative health outcomes associated with physical inactivity and prolonged sitting. Physical activity is any bodily movement produced by the contraction of skeletal muscles that results in a substantial increase in caloric requirements over resting energy expenditure (American College of Sports Medicine, 2013). Evidence indicates that regular PA can improve overall physical function through disease prevention and enhancing overall well-being (Giacobbi et al., 2005; Hogan et al., 2015; U.S. Department of Health and Human Services., 2018a).

Although the health benefits of PA are undeniable, physical inactivity is a growing issue worldwide (Kohl et al., 2012). To prevent illness and reap the benefits of a physically active lifestyle American guidelines recommend: adults 
move more and sit less throughout the day; engage in 150-300 minutes of moderate-intensity movement or 75-100 minutes of vigorous-intensity movement throughout the week; and engage in muscle-strengthening movement for all major muscles twice a week (U. S. Department of Health and Human Services, 2018b). The vast majority of adults do not achieve the recommended guidelines for PA to prevent chronic disease and improve overall physical health (U.S. Department of Health and Human Services, 2018a). More importantly, evidence indicates that even if a person achieves these PA recommendations, there is still a risk for early mortality with high levels of prolonged sitting time throughout the day (Katzmarzyk et al., 2009). Therefore, addressing solutions to improve levels of prolonged sitting time and PA deserves equal attention in preventing the onset of early disease and disability.

The workplace presents itself as a vehicle to change PA and sitting behaviors in the work environment. Moreover, university campuses serve as large worksites that may embody more agency of healthy change among faculty and staff employees that can eventually influence student populations and their communities as a whole in a positive manner. Also, the sedentary behaviors of university faculty and staff employees may be found as similar to other sedentary worksites. An investigative focus on university worksites may generalize results to combat sitting time and increase movement throughout one's workday across workplaces. There has been a steady increase in the prevalence of sedentary occupations since 1960 in the U.S., with a simultaneous increase in average body weight for Americans (Church et al., 2011), which is a known public health concern. In a study that examined worksites of sedentary employees, PA levels, and the risk of metabolic syndrome (a myriad of health risk factors), it was found that sedentary employees had a higher prevalence of metabolic syndrome compared to less sedentary employees (Browne et al., 2017). Additionally, evidence shows that replacing sitting time with standing or any movement improves various cardiometabolic risk factors (Winkler et al., 2018). Moreover, the Office of Disease Prevention and Health Promotion's (2018a) PA scientific report concluded that PA bouts of any length of time contribute to the health benefits associated with the accumulated volume of PA recommendations. Knowing the negative health impact of prolonged sitting, sedentary occupations, and physical inactivity in the adult population presents a public health opportunity to address behavior change in workplaces through worksite wellness program initiatives to increase even small amounts of movement changes.

In the case of the university workplace, light intensity neuromotor PA is more beneficial to engage in rather than merely standing to break up prolonged sitting (Bailey \& Locke, 2015) and is more easily integrated into the workday rather than generalized exercise. Neuromotor PA is considered movement that involves motor skills such as balance, coordination, gait, agility and proprioceptive training and is sometimes referred to as functional movements (American College of Sports Medicine, 2013). These PA behaviors are seen as a more accessible modality of movement in the workplace to break up sitting time (Audrey et al., 2014; Bailey \& Locke, 2015; U.S. Department of Health and Human Services, 2018a). Evidence indicates there are major health benefits that can occur from engaging in light intensity PA for the majority of the population (U. S. Department of Health and Human Services, 2018a; Winkler et al., 2018). Neuromotor PA behaviors are found to improve physical function overall and improve balance and gait (American College of Sports Medicine, 2013; Garber et al., 2011; Liu-Ambrose et al., 2004). Additionally, the majority of the population who fail to participate in the recommended levels of moderate-vigorous PA can reduce the risk of allcause mortality by breaking up prolonged sitting time with light intensity PA (U. S. Department of Health and Human Services, 2018a).

The changes from the 2008 to the 2018 PA scientific report concludes that any amount of movement for any amount of time can make a positive contribution to physical health. This finding may be critical in reducing the anxiety 
many non-movers experience when considering the initial steps needed for moving more throughout their day. Bailey and Locke (2015) examined the effects of breaking up sitting time with gait-based light PA or standing and its impact on cardiometabolic risk factors for adult employees. Their results showed that interrupting sitting time with a short duration of light intensity neuromotor gait-based PA lowered cardiometabolic risk factors more so than merely standing. Neuromotor movements may be overlooked due to their functional component, their ability to replicate everyday movements, or the perception that they are not strenuous enough movement to make a significant impact on physical health. This oversight is due to the notion that for movements to make a difference they must be exercise oriented and take place in a specific domain, such as a gym. It appears there are general health benefits for the overall population if the positive outcomes of light intensity and neuromotor PA modalities rather than general exercise can be disseminated within PA programs and interventions (Duvivier et al., 2017; Füzéki et al., 2017; Garber et al., 2011; Liu-Ambrose et al., 2004). In doing so, efforts can move populations from sedentary and physically inactive to light PA engagement to help break up prolonged sitting.

In order to change university employee PA and sitting behaviors, it is useful to evaluate university worksite wellness initiatives. Health professionals can gain insight into possible solutions to help employees in academic communities get up and perform light neuromotor PA movements at work and consequentially explore why these solutions are successful by evaluating worksite wellness initiatives.

To improve PA levels and prolonged sitting time for employees, worksite wellness PA programs must first understand employee beliefs regarding these specific behaviors. Such efforts could lead the majority of academic communities into a state of PA. According to Fishbein (2008), a person's behavior stems from their beliefs about doing the behavior, and these beliefs ultimately influence if they do or do not do the behavior. The Reasoned Action Approach (RAA) is used to predict behaviors based on individual beliefs about doing a behavior (Fishbein, 2008) and is a widely used theory in studies involving behavior prediction and health behaviors. Using the RAA framework could help better tailor university worksite PA programs to meet this population's need.

The RAA indicates that behavior is influenced by intention, which is influenced by three global constructs: attitude towards the act, perceived norm, and perceived behavioral control. The RAA considers intention as a person's readiness and likeliness to do a particular behavior (Fishbein \& Ajzen, 2010). The theory explains: 1) The attitude toward the act is how a person responds favorably or unfavorably to the behavior, and how they see it as being good or bad for them; 2) perceived norm is a person's perceived social pressure to do the behavior; and 3) perceived behavioral control is how much a person believes they are capable of performing the behavior or that they are in control of doing the behavior. It is necessary to note that a behavior is defined as a viewable action that is directed towards a specific target and takes place in a specific context or setting at a specific time (Fishbein, 2008). Overall, in a simplified sense a person's intention to do a specific behavior is influenced by how fun (attitude towards the act), popular (perceived norm), and easy (perceived behavioral control) they believe the behavior to be (Jimerson et al., 2004).

\section{PURPOSE}

A study of two closely related and simultaneously performed sub-studies was conducted to address getting up and doing light neuromotor PA at work among university sedentary employees. These two sub studies examined the same behavior among employees: getting up and performing three light intensity neuromotor PA movements at work. 
These three movements were always referred to as "The Big 3" when communicating with the two sub-studies participants (Figure 1). The movements included three multi-joint muscle actions. The rationale of selecting these three movements was to allow more opportunities to get up from workstations and improve physical function with specific neuromotor based movements to break up sitting time in the workplace and improve postural imbalances associated with prolonged sitting. The first movement, "Pull Downs," adducts the shoulder unilaterally using a resistance band that targets the latissimus dorsi major muscle group. The second movement, "Sit to Stands," simulates a traditional squat by getting a person up and down from the chair sitting position. This movement uses hip flexion and extension, knee flexion and extension, and primarily targets the gluteus maximus, gluteus medius, and quadriceps muscles. The third movement, "Scrunches," retracts the scapula using a resistance band and targets the rhomboids and middle trapezius muscles. The titles of the movements were intentionally named to make them more relatable to sedentary and less active employees.

The study's first perspective focused on evaluating the effects that a university worksite wellness group PA program could have on employees doing "The Big 3" movements at work. This perspective was the foundation of sub-study 1 and aimed to examine if participation in a weekly thirty-minute group worksite PA program increased the average number of days employees did "The Big 3" movements at work over an eight-week period (pretest to posttest) when compared to non-participating employees.

The second perspective focused on employee belief factors specific to getting up and doing “The Big 3" at work. The objective of the exploratory analysis of sub-study 2 was to utilize the RAA constructs and examine the significance of the easy, popular, and fun beliefs in predicting employee intention to get up and do "The Big 3" at work. 
Figure 1.

\section{Sides of Back}

- With shoulders over hips, raise arms overhead.

- Make a fist and pull one elbow down by your side, squeezing as you go.

- Repeat with other arm.

- Bonus: Add a resistance band.

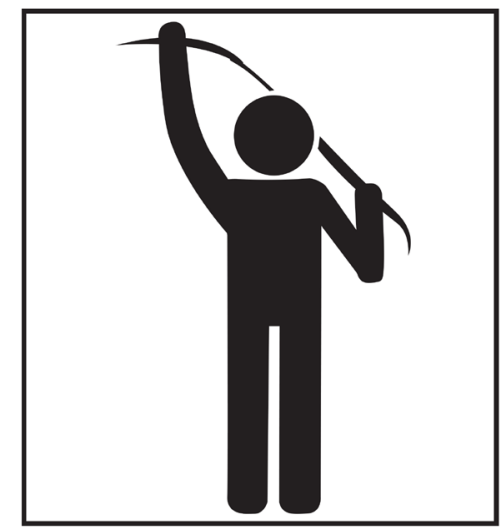

\section{Sit to Stand}

- From seated position, stand using only one leg. Repeat with other leg.

- Bonus: Stand and close eyes; stand and turn head side to side.

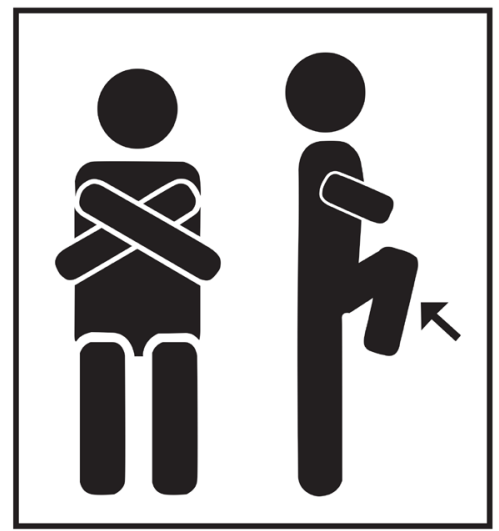

\section{Upper Back}

- With arms at sides, bring forearms parallel with ground.

- Pull elbows back and squeeze shoulder blades together like squeezing a pencil.

- Bonus: Add a resistance band.

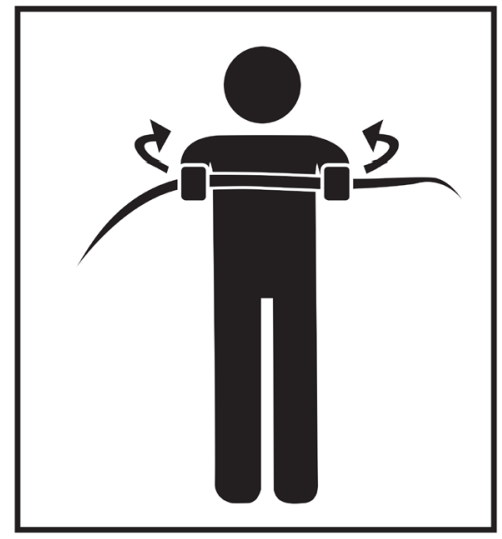

PA has been researched extensively. Yet, there is little research regarding getting up and performing light-intensity neuromotor PA behaviors at work in university settings. Therefore, the study pursued these research questions: 1) Does a weekly thirty minute worksite group PA program have a significant effect on the average number of days employees get up and do the three specific movements at work over an eight week period between employees participating in the program and non-participating employees? 2) Which belief (fun, popular, easy) of The RAA is a 
significant predictor and has the highest regression weight that contributes to the prediction of employee intention to get up and do "The Big 3" in the workplace?

\section{METHODS}

To examine employee intention for performing “The Big 3," two sub-studies were conducted at a large Midwestern university during the same time frame within the university's worksite wellness program. All participants in this study were university employees. The university worksite wellness program at the researcher's university offered the group PA program. This specific university worksite PA program created the common sample recruitment and data collection methods between both sub-studies. The Institutional Review Board of the researchers' university approved this study.

\section{Description of the University Worksite Group Movement Program}

The weekly worksite group PA program was offered through the university's worksite wellness program in partnership with a kinesiology undergraduate course. The worksite group movement program had three distinct characteristics: 1) movement coaches enrolled in the kinesiology academic class provided tailored movement instruction (focused on functional or neuromotor movements centered on strength, flexibility, and balance) for 30 minutes, once a week, over eight weeks in a central location on campus; 2) unlike traditional group exercise classes, the researcher's program placed an emphasis on functionality (i.e., encouraging participants to wear their work clothes to the program instead of changing into athletic attire), thus, integrating movement into the workday specifically; and 3) the group environment differed from a typical group PA experience because of the integration of students interacting with faculty and staff employees, and the interaction among fellow university co-workers while participating in the program.

\section{Sub-Study 1}

Design. Sub-study 1 followed a non-equivalent group design to examine pre and posttest differences between the intervention and control group in the average number of days employees got up and did each of "The Big 3" at work. The intervention group was composed of employees who participated in the weekly thirty-minute group worksite wellness PA program for eight weeks. The control group was composed of employees who did not participate in the program. The average number of days the employees did each of "The Big 3" at work served as the dependent variables. The intervention status of the employee served as the independent variable.

Sample. For both sub-studies, participants were recruited through combined efforts with the university worksite wellness program. The researchers recruited employees enrolled in the university worksite group movement program by email to participate in this study. Once these employees expressed consent to participate in the study, they were asked to nominate one to two fellow co-workers that were not enrolled in the program to be participants of the study. This nomination was done via shared email communication with the researchers. This allowed researchers to recruit and communicate with university employees not associated with the university worksite program. Fifty-six employees were recruited (28 participated in the intervention and 28 did not). A power analysis using G*Power (version 3.1) determined that the sample size $(N=56)$ would generate a moderate effect. A final sub-sample $(N=25)$ for sub- 
study 1 was generated due to the lack of participants that proceeded to complete both the pre and post survey selection criteria. The intervention group $(n=15)$ consisted of the recruited university employees that were 1$)$ enrolled in the worksite group movement program, 2) consented to participating in the study, and 3) completed both pre and posttest online questionnaires. The control group $(n=10)$ consisted of the nominated university employees that were 1$)$ not enrolled in the worksite PA program, 2) consented to participating in the study, and 3) completed both pre and posttest online questionnaires.

Procedures. Once participants were recruited and agreed to participate, they received a resistance band and handout (Figure 1) that provided visual context and instruction for "The Big 3" movements. The intervention group received their resistance band and handout at an orientation meeting one week before the first official worksite group movement experience. The intervention participants also received in-person instructions for "The Big 3" at the initial orientation. The control group received their materials via campus mail delivery upon their consent to participate and received no in-person instruction. One week after receiving their materials, both groups were emailed a pre-survey designed with Qualtrics.

During the last week of the program (eight weeks after the pre-survey was completed) the groups were emailed an online posttest that mimicked the pretest. Throughout that eight-week period, the intervention group received tailored instruction regarding "The Big 3" during the weekly 30-minute group movement PA experience. The control group solely received a delivery of the resistance band, the handout, and email communication to complete surveys during the eight-week period. Both groups received weekly e-mail reminders to get up and do "The Big 3" at work throughout the eight-week course of the study.

Instrument and Measurement Procedures. The pretest instrument began with an informed consent statement followed by four participant characteristic questions: age, gender, sitting time (Katzmarzyk et al., 2009), and perceived general health (U.S. Department of Health and Human Services, 2017).

Sub-study 1 focused on a close-ended item that measured the days employees did each of the three light-intensity neuromotor movements. Employees reported which, if any, of the three movements they did on the three specific workdays. The average number for each of the three movements of three days was measured. Monday, Tuesday, and Wednesday were chosen because the pre and posttests were delivered on Thursdays, and recall was assumed to be easiest for three days compared to a full workweek. The posttest instrument excluded participant characteristics but followed the exact same item and measurement of the days employees did each of the three light intensity neuromotor movements.

Analysis. The data from Qualtrics was imported into SPSS (version 25) for data analysis. Descriptive statistics were utilized to summarize participant characteristic information (Table 1). Due to the small sample size, a Fisher's exact test was used to test the significant association between characteristic variables. The three different movements of "The Big 3" were related variables that each separately served as the dependent variables to be measured at pre and post time points. Therefore, each of the three movements were tracked pre and post in the analysis. A repeated measures MANOVA was deemed the most suitable analysis (Tabachnick et al., 2019). The classification of the groups (intervention or control) served as the between-subjects factor and time of pre and post reports of each of the three movements served as the within-subjects factor. A repeated measures MANOVA was used to examine the main effects of time and group classification on the average number of days employees got up and did each of the three specific and different movements at work. Once significance was found with MANOVA, univariate analyses were then examined for each of the dependent variables. 


\section{Sub-Study 2}

Design. Sub-study 2 followed a descriptive cross-sectional study design to examine if the fun, popular, and easy belief variables of the RAA significantly predicted employee intention to get up and do "The Big 3" at work. Intention served as the dependent variable. The RAA fun, popular, and easy beliefs were the independent variables of the study.

Sample. The same recruitment strategy explained in sub-study 1 created the sample of sub-study 2 and resulted in a larger sample size. The sample of sub-study 2 consisted of employees that only completed one survey (the presurvey in sub-study 1). As a result, there was a larger sample size $(N=56)$. Twenty-eight participants of this sample participated in the group PA program and 28 did not.

Procedures. The sample of 56 employees recruited via nomination or their enrollment with the university worksite group movement PA program received the resistance band and handout materials as identified in the substudy 1 procedures. Once confirmation was received that participants had received these materials, they were sent the online pretest to participate in the study.

Instrument and Measurement Procedures. Close-ended validated items to measure the RAA constructs developed by the founders of the theory, Fishbein \& Ajzen (2010), were used for measurement. Each had a 5-point scale for measurement. Intention was measured by two items: 1) "I plan to get up and do The Big 3 every day at work for the next four weeks" (strongly disagree or strongly agree); and 2) "I will do The Big 3 every day at work for the next four weeks" (strongly disagree or strongly agree). Attitude was measured by two items: 1) "Doing The Big 3 at work every day for the next four weeks is extremely bad or extremely good;" and 2) "Doing The Big 3 at work every day for the next four weeks is extremely boring or extremely fun." Perceived norm was measured by two items: 1) "Most people like me do The Big 3 Movements every day at work" (strongly disagree or strongly agree); and 2) "Most people who are important to me think I should do The Big 3 Movements every day at work for the next four weeks" (strongly disagree or strongly agree). Perceived behavioral control was measured by two items: 1) "My getting up and doing The Big 3 Movements every day at work for the next four weeks is completely not up to me or completely up to me" and 2) "How confident are you that you can do The Big 3 Movements every day at work for the next four weeks?" (not at all confident or extremely confident).

Analysis. Sub-study 2 served as an exploratory analysis for sub-study 1. The data from Qualtrics was imported into SPSS (version 25) for data analysis. The descriptive statistics utilized in sub-study 1 summarized participant characteristics. The close-ended items were all recoded to a consistent 1 to 5 scale. Reliability tests were conducted to measure internal consistency of item measurement. Linear regression was identified as the most suitable to test the three RAA constructs significance in predicting employee intention to get up and do the three specific light intensity neuromotor PA movements at work (Seber \& Lee, 2012). The assumptions of regression were met (i.e., adequate sample size, normality, linearity, homoscedasticity, and absence of outliers, singularity and multicollinearity).

\section{RESULTS}

Table 1 outlines the participant characteristics of the study's total sample $(N=56)$. The majority of participants were between the ages of 38-51 (35.7\%) or between the ages of $23-37$ (30.4\%), female $(82.1 \%)$, reported sitting almost all of the time at work $(44.65 \%)$ or sitting $3 / 4$ of the time $(33.9 \%)$, and perceived their health to be 'good' $(42.9 \%)$. 
Table 1. Participant Characteristics for sub-studies

\begin{tabular}{|c|c|c|c|c|c|c|c|}
\hline \multirow[b]{2}{*}{ Characteristic } & \multicolumn{2}{|c|}{$\begin{array}{l}\text { Total } \\
(\mathrm{n}=56)\end{array}$} & \multicolumn{2}{|c|}{$\begin{array}{l}\text { Intervention } \\
(\mathrm{n}=28)\end{array}$} & \multicolumn{2}{|c|}{$\begin{array}{l}\text { Control } \\
(n=28)\end{array}$} & \multirow[b]{2}{*}{$p$-value } \\
\hline & $\mathrm{N}$ & $\%$ & $\mathrm{~N}$ & $\%$ & $\mathrm{~N}$ & $\%$ & \\
\hline Age & & & & & & & .109 \\
\hline $23-37$ & 19 & $33.9 \%$ & 6 & $21.4 \%$ & 13 & $46.4 \%$ & \\
\hline 38- 51 & 20 & $35.7 \%$ & 13 & $46.4 \%$ & 7 & $25.0 \%$ & \\
\hline $52-69$ & 17 & $30.4 \%$ & 9 & $32.1 \%$ & 8 & $28.6 \%$ & \\
\hline Gender & & & & & & & $1.00^{\mathrm{a}}$ \\
\hline Female & 46 & $82.1 \%$ & 23 & $82.1 \%$ & 23 & $82.1 \%$ & \\
\hline Male & 10 & $17.9 \%$ & 5 & $17.9 \%$ & 5 & $17.9 \%$ & \\
\hline Sitting Time & & & & & & & .448 \\
\hline $\begin{array}{l}\text { Approximately } 1 / 4 \text { of the } \\
\text { time }\end{array}$ & 2 & $3.6 \%$ & 1 & $3.6 \%$ & 1 & $3.6 \%$ & \\
\hline $\begin{array}{l}\text { Approximately } 1 / 2 \text { of the } \\
\text { time }\end{array}$ & 10 & $17.9 \%$ & 3 & $10.7 \%$ & 7 & $25.0 \%$ & \\
\hline $\begin{array}{l}\text { Approximately } 3 / 4 \text { of the } \\
\text { time }\end{array}$ & 19 & $33.9 \%$ & 9 & $32.1 \%$ & 10 & $35.7 \%$ & \\
\hline Almost all of the time & 25 & $44.65 \%$ & 15 & $53.6 \%$ & 28 & $35.7 \%$ & \\
\hline General & & & & & & & .485 \\
\hline \multicolumn{8}{|l|}{ Health } \\
\hline Poor & 2 & $3.6 \%$ & 1 & $3.6 \%$ & 1 & $3.6 \%$ & \\
\hline Fair & 8 & $14.3 \%$ & 2 & $7.1 \%$ & 6 & $21.4 \%$ & \\
\hline Good & 24 & $42.9 \%$ & 14 & $50.0 \%$ & 10 & $35.7 \%$ & \\
\hline Very Good & 14 & $25.0 \%$ & 6 & $21.4 \%$ & 8 & $28.6 \%$ & \\
\hline Excellent & 8 & $14.3 \%$ & 5 & $17.9 \%$ & 3 & $10.7 \%$ & \\
\hline
\end{tabular}

a: Based on Fisher's exact test

Table 2 reports the results of MANOVA comparing pre and post average days employees $(n=25)$ got up and did the three separate "Big 3" movements at work between the intervention and control group. There was significant interaction effect between time and group. Results showed a significant effect between intervention and control group on the average number of days employees got up and did the three specific light intensity neuromotor PA movements over an eight week period, $\mathrm{F}(3,21)=3.16, \mathrm{p}<.05$. The univariate results showed a marginal intervention effect on employee behavior to get up and do two of the three specific movements, $\mathrm{F}(1,23)=2.98, \mathrm{p}=.098$ for Pull Downs and $F(1,23)=3.68 ; p=.068$ for Sit to Stands. 
Table 2. Result of MANOVA Comparing Pre and Post Outcomes of Intervention and Control Groups

\begin{tabular}{|c|c|c|c|c|c|c|c|c|c|c|c|c|c|c|c|}
\hline \multirow{3}{*}{$\begin{array}{l}\text { Rapid } \\
\text { Workstatio } \\
\mathrm{n} \\
\text { Movements }\end{array}$} & \multicolumn{9}{|c|}{ Univariate } & \multicolumn{6}{|c|}{ Multivariate } \\
\hline & \multicolumn{3}{|c|}{ Group Effect } & \multicolumn{3}{|c|}{ Time Effect } & \multicolumn{3}{|c|}{ Group x Time } & $\begin{array}{l}\text { Group } \\
\text { Effect }\end{array}$ & \multicolumn{3}{|c|}{ Time Effect } & \multicolumn{2}{|l|}{$\begin{array}{l}\text { Group } \\
\text { Time }\end{array}$} \\
\hline & MS & $\mathrm{F}$ & $p$ & MS & $\mathrm{F}$ & $p$ & MS & $\mathrm{F}$ & $p$ & $\mathrm{~F}$ & $p$ & $\mathrm{~F}$ & $p$ & $\mathrm{~F}$ & $p$ \\
\hline \multirow{2}{*}{ Pull Downs } & 2.08 & 1.26 & .27 & .03 & \multirow{2}{*}{.025} & .87 & 3.63 & 2.97 & .098 & .90 & .45 & 1.43 & .26 & 3.16 & \multirow{2}{*}{$\begin{array}{l}.046 \\
*\end{array}$} \\
\hline & 3 & 4 & 3 & 0 & & 7 & 0 & 6 & $\mathrm{~m}$ & 7 & 5 & 7 & 0 & 4 & \\
\hline Upper Back & 1.76 & \multirow{2}{*}{.928} & .34 & 2.0 & 1.92 & .17 & \multirow{2}{*}{.163} & \multirow{2}{*}{.151} & \multirow{2}{*}{.701} & & & & & & \\
\hline Scrunches & 3 & & 5 & 8 & 3 & 9 & & & & & & & & & \\
\hline Sit & 013 & 008 & .93 & .00 & 0 & 1.0 & 4.32 & 3.68 & .068 & & & & & & \\
\hline Stands & .013 & .000 & 1 & 0 & .000 & 0 & 0 & 0 & $\mathrm{~m}$ & & & & & & \\
\hline
\end{tabular}

Note: $\mathrm{MS}=$ mean square; $p=p$-value

$* \mathrm{p}<.05, \mathrm{~m}=$ marginal significance $\mathrm{p}<.10$

Table 3 indicates the pre and post mean number of days employees got up and did the three specific "Big 3" at work between the intervention and control groups. Overall, the total average number of days employees got up and did the three separate movements at work was less than one day at the pretest and then averaged one day after eight weeks at posttest measurement. Moreover, the intervention group increased the average number of days they got up and did "The Big 3" at work from pre to post measurement. For the majority, the control group decreased the average number of days they got up and did "The Big 3" at work from pre to post measurement.

Table 3. The Average Number of Days of Doing Three Light Intensity Neuromotor PA Movements At Work Outcomes Between Intervention and Control Groups

\begin{tabular}{|c|c|c|c|c|c|c|}
\hline \multirow[b]{2}{*}{ Rapid Workstation Movements } & \multicolumn{2}{|c|}{$\begin{array}{l}\text { Total } \\
(n=25)\end{array}$} & \multicolumn{2}{|c|}{$\begin{array}{l}\text { Intervention } \\
(\mathrm{n}=15)\end{array}$} & \multicolumn{2}{|c|}{$\begin{array}{l}\text { Control } \\
(\mathrm{n}=10)\end{array}$} \\
\hline & Pre & Post & Pre & Post & Pre & Post \\
\hline Pull Downs & .92 & 1.08 & .53 & 1.13 & 1.50 & 1.00 \\
\hline Upper Back Scrunches & .80 & 1.24 & .60 & 1.13 & 1.10 & 1.40 \\
\hline Sit to Stands & .92 & 1.04 & .67 & 1.27 & 1.30 & .70 \\
\hline
\end{tabular}

Table 4 shows the results of reliability tests for sub-study 2. Reliability analysis confirmed the two-item measure of intention (Cronbach's $\alpha .876$ ) with a mean $=3.67$, the 2 -item measure of attitude toward the act (Cronbach's $\alpha$ .487) with a mean $=4.05$, a 2 -item measure for perceived norm (Cronbach's $\alpha .573$ ) with a mean $=2.96$, and a 2-item measure for perceived behavioral control (Cronbach's $\alpha .489$ ) with a mean $=3.71$. Cronbach's alpha ranged from $.489-.876$ for the three global constructs used in measurement, which confirms their reliability. 
Table 4. Reliability Results of Reasoned Action Approach Constructs

$\begin{array}{lllll}\text { Constructs } & \text { Number of Items } & \text { Mean } & \text { Standard Deviation } & \text { Cronbach's Alpha } \\ \text { Intention } & 2 & 3.67 & .936 & .876 \\ \begin{array}{l}\text { Attitude Toward the } \\ \text { Act }\end{array} & 2 & 4.05 & .570 & .487 \\ \begin{array}{l}\text { Perceived Norm } \\ \text { Perceived Behavioral }\end{array} & 2 & 3.09 & .890 & .837 \\ \text { Control } & 2 & 3.71 & .868 & .489\end{array}$

Table 5 reports the results of a linear regression model of the three global constructs (attitude toward the act, perceived norm, and perceived behavioral control) to predict employee intention to get up and do "The Big 3" at work. The three global constructs each showed a positive Pearson correlation with employee intention to get up and do these movements in the workplace. An adjusted $r$-squared of $.343, p<.001$ indicates that the three global constructs accounted for $34.3 \%$ of the variance in intention and explained a significant proportion of variance in intention scores. Perceived norm (popular) and perceived behavioral control (easy) were the two constructs found to be significant. Perceived behavioral control, or the "easy belief," had the highest regression weight score $\beta=.433, p<.001$. While perceived norm, or the "popular belief," followed $\beta=.353, p<.01$.

Table 5. Linear Regression Model Predicting Intention to Get Up and Do Three Light Intensity Neuromotor PA Movements At Work $(\mathrm{N}=56)$

\begin{tabular}{llllll}
\hline Predictor Variable & Pearson $\mathrm{r}$ & $\mathrm{B}$ & SE B & $\beta$ & $p$-value \\
\hline Attitude Toward the Act & .222 & -.029 & .194 & -.018 & .882 \\
$\begin{array}{l}\text { Perceived Norm } \\
\text { Perceived Behavioral }\end{array}$ & .455 & .371 & .121 & .353 & $.004^{* *}$ \\
Control & .514 & .467 & .126 & .433 & $.001^{* * *}$ \\
\hline
\end{tabular}

Note: Adjusted $\mathrm{R}^{2}=.343$

${ }^{*} \mathrm{p}<.05 ;{ }^{* *} \mathrm{p}<.01 ; * * * \mathrm{p}<.001$

\section{DISCUSSION}

The study's findings showed a significant interaction of group and time on the average number of days employees got up and did three specific light intensity neuromotor PA movements at work. This finding implies that a group dynamic serves as a mechanism for change by increasing one's intention to replace sitting time with specific PA behaviors. Such change is argued to occur due to the group dynamic's ability to positively influence one's beliefs that ultimately influence one's intention to get up and engage in light intensity neuromotor behaviors in the workplace. Consequently, this specific finding implies a translational application for worksite wellness PA programs to consider, i.e., a group design to improve university employee PA levels while addressing prolonged sitting time. Such results concur with evidence that adults are more physically active overall when they participate in group PA setting compared to doing PA alone (Firestone et al., 2015). These complimentary results suggest participating in a group worksite PA program 
can be more successful in influencing employee PA behaviors over time compared to merely giving employees educational handouts like the control group received.

The statistical significance of perceived norm in predicting employee intention to get up and do "The Big 3" at work complements the previous finding of sub-study 1. This "popular" variable was a significant predictor of employee intention, which supports previous studies that show this construct as significant in predicting intention (Busse \& Miranda, 2018; Hagger et al., 2002; Kerner \& Grossman, 1998). Since intention is the most proximal factor that leads to behavior, university wellness programs can practically apply this finding by increasing efforts to make getting up and doing light intensity neuromotor PA at work a more popular and normative behavior. A worksite group PA program is an opportunity to create an environment for employees to see co-workers like them doing the behavior in a group setting, which reinforces their normative belief, and positively influences their intention to get up at work and do light intensity neuromotor PA movements. This implication echoes the Deinhart and KennedyArmbruster (2019) study, which found positive PA behavioral change among university employees that participated in worksite PA programs with other employees and students.

Perceived behavioral control was a significant predictor of employee intention to get up and do "The Big 3" and had the highest regression weight. This finding supports previous researchers who also reported that out of the three global constructs in the RAA, perceived behavioral control has the highest regression weight for predicting PA behavior intention (Busse \& Miranda, 2018; Conner et al., 2017). This study observed a low average number of days employees got up and did three separate light intensity neuromotor PA movements at work regardless of their enrollment status in a worksite wellness PA program. These results suggest that making this behavior appear easier may help university wellness programs improve employee PA and prolonged sitting time outcomes. For example, efforts that aim to improve PA levels as a means to help decrease prolonged sitting may translate this finding into action by starting sedentary employees off with basic movements in worksite PA initiatives. Starting with low-skill level movements can increase perceived behavioral control more so than introducing them to moderate-vigorous intensity or complex PA movements at the start of a worksite PA program.

It is interesting to note that attitude towards the act was not found to be a significant predictor of employee intention. The results indicate that efforts may no longer find significant behavior change by solely focusing on increasing attitude. However, future research may need to examine attitude towards prolonged sitting time to further understand beliefs regarding the issue of sedentary or prolonged sitting behaviors specifically.

The RAA served as the theoretical framework in this study as a whole, with the overarching purpose to examine behavioral aspects and predictors of intention to get up and do specific PA behaviors at work. This theory accounts for belief constructs that impact one's intention, the main determinant of behavior (Fishbein, 2008). This study focused on identifying global constructs that significantly impacted intention and how these constructs may be applied in PA program and intervention designs. There is implication for future research focused on influencing PA behaviors to also consider a complimentary framework to include models such as the Transtheoretical Model of Behavior Change (Prochaska et al., 2009) or the Self-Determination Theory (Deci \& Ryan, 2012). These theories have been used as investigative frameworks in studies with PA or exercise behavioral objectives. A complimentary theoretical approach could demonstrate how various constructs may influence one's relationship with intention to engage in PA behaviors that The RAA alone may not fully address.

This study is not without limitations. The small sample size of both studies and recruitment from one site are clear limitations. Future research should focus efforts to increase the sample size to enhance the validity and reliability 
of results. Also, a true random assignment of the groups from various sites should be pursued in future research, similar to sub-study 1 , to increase generalizability of results.

\section{CONCLUSION}

Improving general PA in the workplace and reducing prolonged sitting time levels is a public health priority. These findings suggest that encouraging university employees to engage in group worksite PA programs with a focus on increasing how popular and easy employees believe getting up and moving at work to be has the potential to address these imminent health issues. 


\section{REFERENCES}

American College of Sports Medicine. (2013). ACSM's Guidelines for Exercise Testing and Prescription. Lippincott Williams \& Wilkins.

Audrey, S., Procter, S., \& Cooper, A. R. (2014). The contribution of walking to work to adult physical activity levels: A cross sectional study. International Journal of Behavioral Nutrition and Physical Activity, 11(1), 37. https://doi.org/10.1186/1479-5868-11-37

Bailey, D. P., \& Locke, C. D. (2015). Breaking up prolonged sitting with light-intensity walking improves postprandial glycemia, but breaking up sitting with standing does not. Journal of Science and Medicine in Sport, 18(3), 294-298. https://doi.org/10.1016/j.jsams.2014.03.008

Browne, R. A. V., Farias-Junior, L. F., Freire, Y. A., Schwade, D., Macêdo, G. de A. D. de, Montenegro, V. B., Lopes, T. J. A., Dantas, F. F. O., \& Costa, E. C. (2017). Sedentary Occupation Workers Who Meet the Physical Activity Recommendations Have a Reduced Risk for Metabolic Syndrome: A Cross-Sectional Study. Journal of Occupational and Environmental Medicine, 59(11), 1029-1033. https://doi.org/10.1097/JOM.0000000000001104

Busse, P., \& Miranda, J. J. (2018). Perceived behavioral control as a potential precursor of walking three times a week: Patient’s perspectives. PLOS ONE, 13(2), e0192915. https://doi.org/10.1371/journal.pone.0192915

Church, T. S., Thomas, D. M., Tudor-Locke, C., Katzmarzyk, P. T., Earnest, C. P., Rodarte, R. Q., Martin, C. K., Blair, S. N., \& Bouchard, C. (2011). Trends over 5 Decades in U.S. Occupation-Related Physical Activity and Their Associations with Obesity. PLOS ONE, 6(5), e19657. https://doi.org/10.1371/journal.pone.0019657

Conner, M., McEachan, R., Lawton, R., \& Gardner, P. (2017). Applying the reasoned action approach to understanding health protection and health risk behaviors. Social Science \& Medicine, 195, 140-148. https://doi.org/10.1016/j.socscimed.2017.10.022

Deci, E. L., \& Ryan, R. M. (2012). Self-Determination Theory. In Handbook of Theories of Social Psychology: Volume 1 (Vol. 1-1, pp. 416-437). SAGE Publications Ltd. https://doi.org/10.4135/9781446249215.n21

Deinhart, M., \& Kennedy-Armbruster, C. (2019). Ready to Move: A Unique University Worksite Wellness Initiative. Building Healthy Academic Communities Journal, 3(1), 7-16. https://doi.org/10.18061/bhac.v3i1.6591

Duvivier, B. M. F. M., Schaper, N. C., Hesselink, M. K. C., van Kan, L., Stienen, N., Winkens, B., Koster, A., \& Savelberg, H. H. C. M. (2017). Breaking sitting with light activities vs structured exercise: A randomised crossover study demonstrating benefits for glycaemic control and insulin sensitivity in type 2 diabetes. Diabetologia, 60(3), 490-498. https://doi.org/10.1007/s00125-016-4161-7

Firestone, M. J., Yi, S. S., Bartley, K. F., \& Eisenhower, D. L. (2015). Perceptions and the role of group exercise among New York City adults, 2010-2011: An examination of interpersonal factors and leisure-time physical activity. Preventive Medicine, 72, 50-55. https://doi.org/10.1016/j.ypmed.2015.01.001

Fishbein (2008). A Reasoned Action Approach to Health Promotion. Medical Decision Making, 28(6), 834-844. https://doi.org/10.1177/0272989X08326092

Fishbein, M., \& Ajzen, I. (2010). Prediction and Change of Behavior: The Reasoned Action Approach. Psychology Press. https://doi.org/10.4324/9780203838020 
Füzéki, E., Engeroff, T., \& Banzer, W. (2017). Health Benefits of Light-Intensity Physical Activity: A Systematic Review of Accelerometer Data of the National Health and Nutrition Examination Survey (NHANES). Sports Medicine, 47(9), 1769-1793. https://doi.org/10.1007/s40279-017-0724-0

Garber, C. E., Blissmer, B., Deschenes, M. R., Franklin, B. A., Lamonte, M. J., Lee, I.-M., Nieman, D. C., \& Swain, D. P. (2011). Quantity and Quality of Exercise for Developing and Maintaining Cardiorespiratory, Musculoskeletal, and Neuromotor Fitness in Apparently Healthy Adults: Guidance for Prescribing Exercise. Medicine \& Science in Sports \& Exercise, 43(7), 1334-1359. https://doi.org/10.1249/MSS.0b013e318213fefb

Giacobbi, P. R., Hausenblas, H. A., \& Frye, N. (2005). A naturalistic assessment of the relationship between personality, daily life events, leisure-time exercise, and mood. Psychology of Sport and Exercise, 6(1), 67-81. https://doi.org/10.1016/j.psychsport.2003.10.009

Hagger, M. S., Chatzisarantis, N. L. D., \& Biddle, S. J. H. (2002). A Meta-Analytic Review of the Theories of Reasoned Action and Planned Behavior in Physical Activity: Predictive Validity and the Contribution of Additional Variables. Journal of Sport \& Exercise Psychology, 31. https://doi.org/10.1123/jsep.24.1.3

Hogan, C. L., Catalino, L. I., Mata, J., \& Fredrickson, B. L. (2015). Beyond emotional benefits: Physical activity and sedentary behaviour affect psychosocial resources through emotions. Psychology \& Health, 30(3), 354-369. https://doi.org/10.1080/08870446.2014.973410

Jimerson, A., Rosenbaum, J., Middlestadt, S., Schneider, A., Strand, J., Mitchell, P., ... \& French, J. (2004). Applying the BEHAVE Framework: A Workshop on Strategic Planning for Behavior Change: FacilitatorÆs Guide. Washington DC: $A E D$

Katzmarzyk, P. T., Church, T. S., Craig, C. L., \& Bouchard, C. (2009). Sitting Time and Mortality from All Causes, Cardiovascular Disease, and Cancer. Medicine \& Science in Sports \& Exercise, 41(5), 998-1005. https://doi.org/10.1249/MSS.0b013e3181930355

Kerner, M. S., \& Grossman, A. H. (1998). Attitudinal, Social, and Practical Correlates to Fitness Behavior: A Test of the Theory of Planned Behavior. Perceptual and Motor Skills, 87(3 suppl), 1139-1154. https://doi.org/10.2466/pms.1998.87.3f.1139

Kohl, H. W., Craig, C. L., Lambert, E. V., Inoue, S., Alkandari, J. R., Leetongin, G., \& Kahlmeier, S. (2012). The pandemic of physical inactivity: Global action for public health. The Lancet, 380(9838), 294-305. https://doi.org/10.1016/S0140-6736(12)60898-8

Liu-Ambrose, T., Khan, K. M., Eng, J. J., Lord, S. R., \& McKay, H. A. (2004). Balance Confidence Improves with Resistance or Agility Training. Gerontology, 50(6), 373-382. https://doi.org/10.1159/000080175

Prochaska, J. O., Johnson, S., \& Lee, P. (2009). The Transtheoretical Model of behavior change. In The handbook of health behavior change, 3rd ed (pp. 59-83). Springer Publishing Company.

Seber, G. A. F., \& Lee, A. J. (2012). Linear Regression Analysis. John Wiley \& Sons.

Tabachnick, B. G., Fidell, L. S., \& Ullman, J. B. (2019). Using multivariate statistics (Seventh edition). Pearson.

U. S. Department of Health and Human Services. (2018a). Physical activity guidelines advisory committee scientific report. Washington (DC): US Department of Health and Human Services. 
U.S. Department of Health and Human Services. (2017). Centers for Disease Control and Prevention (CDC). Behavioral Risk Factor Surveillance System Survey Questionnaire. Centers for Disease Control and Prevention.

U.S. Department of Health and Human Services. (2018b). Physical Activity Guidelines for Americans, 2nd edition.

Winkler, E. a. H., Chastin, S., Eakin, E. G., Owen, N., Lamontagne, A. D., Moodie, M., Dempsey, P. C., Kingwell, B. A., Dunstan, D. W., \& Healy, G. N. (2018). Cardiometabolic Impact of Changing Sitting, Standing, and Stepping in the Workplace. Medicine \& Science in Sports \& Exercise, 50(3), 516-524. https://doi.org/10.1249/MSS.0000000000001453

Address author correspondence to:

Jaclyn Hadfield, Ph.D.

Indiana University - Bloomington

School of Public Health

Department of Applied Health Science

1025 East $7^{\text {th }}$ Street

Bloomington, IN 47404

jhadfiel@indiana.edu 